\title{
Suicidal patients in a psychiatric emergency unit: clinical characteristics and aggression profile
}

\author{
Pacientes suicidas em uma unidade de emergência psiquiátrica: características \\ clínicas e perfil de agressão
}

\author{
Vítor Crestani Calegaro, ${ }^{1,2}$ (D) Cleonice Zatti, ${ }^{1}$ (D) Andre Goettems Bastos, ${ }^{3}$ Lucia Helena Machado Freitas ${ }^{1}$
}

\begin{abstract}
Objective: To explore and describe a profile of patients admitted to a psychiatric emergency facility, comparing patients with and without a recent suicide attempt in terms of their clinical characteristics and aggression.

Methods: This was an exploratory comparative study where patients were assessed using the Brief Psychiatric Rating Scale (BPRS) and the Overt Aggression Scale (OAS). Participants with a suicide attempt in the last 24 hours (SA) were compared to participants with a prior history of suicide attempt but no recent attempt (PHSA).

Results: 63 individuals (SA: 26; PHSA: 37) were selected. Both groups had similar demographic and clinical characteristics. The most prevalent diagnoses were mood $(57.1 \%)$ and personality $(50.8 \%)$ disorders. The majority of patients in both groups had a history of aggression episodes. Physical aggression in the week prior to admission was more prevalent in the PHSA group (51.4 vs. $19.2 \%, p=0.017)$. The PHSA group also presented higher activation scores $(p=0.025)$, while the SA group presented higher affect scores on BPRS dimensions $(p=0.002)$.

Conclusion: The majority of individuals with a history of suicide attempt also presented a history of aggression. Inpatients with recent suicide attempt were hospitalized mainly due to the risk of suicide, while those with no recent suicide attempt were hospitalized mainly due to the risk of hetero-aggression. These findings support the hypothesis of an aggressive profile in suicidal patients and may open up a path for future research.

Keywords: Suicide attempt, aggression, public health.
\end{abstract}

\section{Resumo}

Objetivo: Explorar e descrever o perfil de pacientes internados em uma unidade de emergência psiquiátrica, comparando os pacientes com e sem tentativa recente de suicídio em termos de suas características clínicas e agressividade.

Métodos: Trata-se de um estudo exploratório comparativo, onde os pacientes foram avaliados por meio da Escala Breve de Avaliação Psiquiátrica (BPRS) e da Escala de Agressividade Declarada (OAS). Os participantes com tentativa de suicídio (TS) nas últimas 24 horas foram comparados com participantes com história prévia de tentativa de suicídio, mas sem tentativa recente (HPTS).

Resultados: Foram selecionados 63 indivíduos (TS: 26; HPTS: 37). Ambos os grupos tinham características demográficas e clínicas semelhantes. Os diagnósticos mais prevalentes foram transtornos de humor $(57,1 \%)$ e de personalidade $(50,8 \%)$. A maioria dos pacientes em ambos os grupos apresentava história de agressão. A agressão física na semana anterior à internação foi mais prevalente no grupo HPTS $(51,4$ vs. $19,2 \%, \mathrm{p}=$ $0,017)$. O grupo HPTS também apresentou maior ativação ( $p=$ $0,025)$, enquanto o grupo TS apresentou maior afetividade nas dimensões da BPRS $(p=0,002)$.

Conclusão: A maioria dos indivíduos com história de tentativa de suicídio também apresentou história de agressão. Os pacientes internados com tentativa recente de suicídio foram hospitalizados principalmente devido ao risco de suicídio, enquanto aqueles sem tentativa recente de suicídio foram hospitalizados principalmente devido ao risco de heteroagressão. Esses achados apoiam a hipótese de um perfil agressivo em pacientes suicidas e podem abrir caminho para pesquisas futuras.

Descritores: Tentativa de suicídio, agressão, saúde pública.

\footnotetext{
1 Programa de Pós-Graduação em Psiquiatria e Ciências do Comportamento, Universidade Federal do Rio Grande do Sul (UFRGS), Porto Alegre, RS, Brazil. 2 Departamento de Neuropsiquiatria, Universidade Federal de Santa Maria (UFSM), Santa Maria, RS, Brazil. ${ }^{3}$ Programa de Pós-Graduação em Psicologia, Pontifícia Universidade Católica do Rio Grande do Sul (PUCRS), Porto Alegre, RS, Brazil.

Submitted Dec 26 2017, accepted for publication May 172018.

Suggested citation: Calegaro VC, Zatti C, Bastos AG, Freitas LHM. Suicidal patients in a psychiatric emergency unit: clinical characteristics and aggression profile. Trends Psychiatry Psychother. 2019;41(1):9-17. Epub Aug 23 2018. http://dx.doi.org/10.1590/2237-6089-2017-0149
} 


\section{Introduction}

Suicide is a global issue and a serious public health problem. ${ }^{1}$ According to the World Health Organization (WHO), approximately one million people commit suicide each year worldwide. It is the second leading cause of death among people aged 15 to 29 years. ${ }^{1}$ The Brazilian Mortality Information System (Sistema de Informação sobre Mortalidade [SIM-2013]) reports that the suicide rate in Rio Grande do Sul is the highest in Brazil (10.18 per 100,000 inhabitants). ${ }^{2}$ The mesoregion of east-central Rio Grande do Sul ranks first (15.96), and the center-west sits in fifth place (10.04). Both easily surpass the national mean of 5.01 per 100,000 inhabitants. ${ }^{2}$ There has been a rise in the mortality rate by suicide among the youth in recent years, although it is still more frequent in the elderly. ${ }^{3}$

Suicide attempts are common and constitute a serious problem for public health, thus it is very important to evaluate risk factors for suicidal behavior, in order to plan strategies for its monitoring and prevention, as well as intervention strategies. Previous self-harm is considered a major risk factor, while mental disorder severity, aggression, impulsivity, and hopelessness seem to predispose to suicide. ${ }^{4}$ The relationship between suicide, aggression and impulsivity was investigated in a postmortem study that showed that impulsive-aggressive traits play a greater role in suicide, particularly in younger individuals. ${ }^{5}$ Other studies have shown that aggression, impulsivity, and suicidality can be understood as interrelated personality facets. ${ }^{6,7}$

Thus, the objective of the present study was to describe a profile of the patients admitted to a psychiatric emergency facility, comparing patients with a recent suicide attempt vs. patients with a previous history of suicide attempt but not a recent attempt. This comparison will focus on their clinical characteristics and history of aggression, as aggression is one of the risk factors for suicide attempt.

\section{Method}

This was an exploratory comparative study without a control group. It was carried out to evaluate suicidal patients admitted to the Psychiatry Service of Hospital Universitário de Santa Maria (HUSM) over a 6-month period. The HUSM is a high-complexity hospital affiliated with the Brazilian Unified Health System (Sistema Único de Saúde [SUS]). It is a reference center for 42 cities in central Rio Grande do Sul, serving approximately 500,000 people. The Psychiatric Service comprises a Psychiatric Emergency Department and a Psychiatric Unit.

This work is part of a larger study that investigated aggressive behavior in psychiatric hospitalization. The methodology employed is fully described elsewhere. ${ }^{8}$ This was a cross-sectional study that included psychiatric inpatients aged between 18 and 65 years. Subjects with a diagnosis of delirium were excluded. Individuals subjected to clinical hospitalization due to suicide attempts were transferred to the Psychiatric Unit after initial clinical management. For the present study, we selected all participants who had attempted suicide in the 24 hours prior to admission (SA) and those who had a prior history of suicide attempt but no recent attempt (PHSA).

\section{Instruments}

Every day the researchers visited the units to interview patients and fill out the research instruments: a research form, the Brief Psychiatric Rating Scale (BPRS), and the Overt Aggression Scale (OAS). ${ }^{9,10}$ The research form was used to collect demographic data, clinical characteristics, and personal and family medical history. Diagnoses were coded according to the International Classification of Diseases, 10th revision (ICD-10), considering what was indicated in the chart at discharge; diagnoses were previously discussed by at least two professionals of the psychiatric medical staff (a medical resident and his supervisor). Evaluation of risks upon admission (suicide, aggression, exposition, etc.) was made based on clinical judgement by the physician on duty, and recorded upon admission.

The anchored version of the BPRS, with 18 items, scored with the help of the corresponding Structured Interview Guide (SIG-BPRS), was used. ${ }^{11,12}$ Symptom scores were obtained according to the factors proposed in the metanalysis by Shafer: affect (depressive mood, anxiety, guilt feelings, and somatic concern), positive symptoms (unusual thought content, hallucinatory behavior, grandiosity, and conceptual disorganization), negative symptoms (blunted affect, emotional withdrawal, and motor retardation), resistance (hostility, uncooperativeness, and suspiciousness), and activation (excitement, tension and mannerisms-posturing). ${ }^{13}$ These instruments were applied at the time of patient admission.

The OAS was used to record the episodes of aggression that occurred in the hospital. The instrument divides episodes into four types: verbal aggression, physical aggression against objects, physical aggression against self, physical aggression against other people. ${ }^{14}$ The instrument was applied daily throughout the patient's stay. History of aggression was assessed using the same criteria adopted for the OAS. 


\section{Statistical analysis}

Analyses were performed using the Statistical Package for the Social Sciences (SPSS) version 23. Frequency tables with categorical variables were constructed and a descriptive analysis of continuous variables was performed. Normality was tested using the Shapiro-Wilk test, and none of the variables was normally distributed. For the comparisons between variables, the Mann-Whitney $U$ test was used for nonnormal continuous variables and ordinal variables. Categorical variables were compared using Fisher's exact test $(2 \times 2$ tables $)$ and a chi-square test. The significance level used for the tests was $a=0.05$.

\section{Ethical considerations}

The local ethics committee approved this study. It was registered in the Brazilian Research Ethics Database under no. CAAE 02232612.3.0000.5346. All patients signed an informed consent form.

\section{Results}

Of the 152 general psychiatric admissions registered during the period of the study and meeting the inclusion criteria, 139 patients were available to be interviewed by the researchers (13 left the hospital before the interview because they were subjected to a short period of observation only). Another two patients were excluded because they had a diagnosis of delirium. Of the 137 patients interviewed in the prior study, 63 were selected to the present analysis. There were 28 cases of suicide attempts in the 24 hours prior to admission (SA group). Two subjects were admitted twice due to suicide attempts over the time of the study, but only one admission was considered. Table 1 presents the general characteristics of the sample.

In the SA group, five participants (7.9\%) had no prior history of suicide attempt. The mean number of suicide attempts was $3.1( \pm 3.0)$, with no statistically significant differences between the groups. Figure 1 illustrates the frequencies and methods of suicide attempts in the 24 hours prior to admission as well as those that occurred previously among participants. The two groups (SA and PHSA) were comparable regarding methods used in past suicide attempts (no significant difference). Violent methods for suicide attempts within 24 hours of admission (hanging, self-cutting, jumping from height, and vehicular impact) were used in $68 \%$ of the cases, and non-violent methods were used in $32 \%$.

Participants had, on average, an income of $\mathrm{R} \$$ $1,654.85 \pm 1,330.38$ per month, and their disorders had begun at $25.4 \pm 12.5$ years of age. There was no significant difference between the groups regarding these variables. Age at the beginning of psychiatric treatment was lower in the PHSA group $(\bar{x}=32 \pm 13$ vs. $\bar{x}=25 \pm 12 ; p=0.043)$, and the SA group had been on psychiatric treatment for less time $(\bar{x}=5.5 \pm 7.4$ years vs. $\bar{x}=11.6 \pm 10.4$ years; $p=0.002)$.

There were differences between genders in the SA group in some variables. The majority of men were not followed by a mental health professional $(81.8 \%)$, and this was the first visit to HUSM for many of them (72.7\%). Meanwhile, $73.3 \%$ of the women had a relationship ( $p$ $=0.015$ ) and $80.0 \%$ had already had an appointment and had fewer previous psychiatric hospitalizations $(p=0.015)$. No gender differences were observed with regard to these variables in the PHSA group.

Substance intoxication was evident during assessment in 14 patients (22.2\%), most commonly by multiple substances $(n=8 ; 12.7 \%)$, followed by alcohol alone ( $n=6 ; 9.5 \%)$, considering the total sample. These variables did not show statistical associations between the groups.

Hospitalization was voluntary in the majority of cases ( $\mathrm{n}=37 ; 58.7 \%$ ). Admission voluntariness was not associated with suicide attempt but was associated with aggression. Sixteen individuals involuntarily admitted $(61.5 \%)$ were aggressive within the first 24 hours in the hospital, compared to only four of the voluntarily admitted $(10.8 \%)$. These differences were significant $(p<0.001)$.

A family member brought the patient to the hospital in 31 cases $(49.2 \%)$. Police or ambulance emergency services brought patients in 16 cases (25.4\%). Patients arrived at the hospital by themselves in six cases (9.5\%).

The most common psychiatric diagnosis was mood disorder (F30-F39, 36 patients, 57.1\%). Of the total sample, 24 patients (38.1\%) were diagnosed with bipolar disorder, 19 (30.2\%) with a manic, hypomanic, or mixed episode, 4 (6.3\%) with a depressive episode, and $11(17.5 \%)$ with recurrent or major depressive disorder. Other prevalent diagnostic categories were personality disorders (F60.0-F60.9, 32 patients, $50.8 \%)$, substance use disorders (F10-F19, 16 patients, $25.4 \%$ ), and psychotic disorders (F20-F29, 9 patients, $14.3 \%)$. There were no significant differences between the groups regarding these variables.

The majority of individuals were using some psychopharmaceutical at the time of admission (71.4\%); however, $63.5 \%$ used it irregularly. Figure 2 shows the types of medications in use. A statistically significant difference was found only for the use of lithium.

A statistically significant association was found for reason for admission. In the SA group, suicide risk was cited most often ( 88.5 vs. $24.3 \%$; $p<0.001$ ), while in the PHSA group, the risk of hetero-aggression was 
Table 1 - Comparison of demographic variables of individuals in the two groups

\begin{tabular}{|c|c|c|c|c|c|}
\hline & \multicolumn{2}{|c|}{ PHSA } & \multicolumn{2}{|c|}{ SA } & \multirow[b]{2}{*}{$\mathbf{p}$} \\
\hline & $\mathbf{n}$ & $\%$ & $\mathbf{n}$ & $\%$ & \\
\hline \multicolumn{6}{|l|}{ Gender } \\
\hline Male & 17 & 45.9 & 11 & 42.3 & 0.082 \\
\hline Female & 20 & 54.1 & 15 & 57.7 & \\
\hline Total & 37 & 100 & 26 & 100 & \\
\hline Age (mean and SD) & 37 & 11 & 38 & 12 & 0.625 \\
\hline \multicolumn{6}{|l|}{ Age range } \\
\hline $18-25$ & 6 & 16.2 & 4 & 15.4 & 0.225 \\
\hline $26-35$ & 13 & 35.1 & 11 & 42.3 & \\
\hline $36-45$ & 7 & 18.9 & 3 & 11.5 & \\
\hline $46-55$ & 11 & 29.7 & 5 & 19.2 & \\
\hline $56-65$ & 0 & 0.0 & 3 & 11.5 & \\
\hline \multicolumn{6}{|l|}{ Education } \\
\hline Primary education not completed & 18 & 48.6 & 11 & 44.0 & 0.388 \\
\hline Primary education completed & 6 & 16.2 & 7 & 28.0 & \\
\hline Secondary education completed & 11 & 29.7 & 4 & 16.0 & \\
\hline Post-secondary education completed* & 2 & 5.4 & 3 & 12.0 & \\
\hline \multicolumn{6}{|l|}{ Race } \\
\hline White & 25 & 67.6 & 15 & 57.7 & 0.423 \\
\hline \multicolumn{6}{|l|}{ Marital status } \\
\hline Single, separated, or widowed & 30 & 81.1 & 17 & 65.4 & 0.159 \\
\hline Married or in a stable union & 7 & 18.9 & 9 & 34.6 & \\
\hline \multicolumn{6}{|l|}{ Living arrangement $^{+}$} \\
\hline Alone & 1 & 2.7 & 6 & 24.0 & 0.014 \\
\hline With partner or family & 36 & 97.3 & 19 & 76.0 & \\
\hline \multicolumn{6}{|l|}{ Has children } \\
\hline Yes & 19 & 51.4 & 14 & 53.8 & 0.845 \\
\hline \multicolumn{6}{|l|}{ Has own income } \\
\hline Yes & 22 & 59.5 & 18 & 69.2 & 0.428 \\
\hline \multicolumn{6}{|l|}{ Occupation } \\
\hline Not working & 15 & 40.5 & 8 & 30.8 & 0.231 \\
\hline Working & 7 & 18.9 & 11 & 42.3 & \\
\hline On disability insurance & 5 & 13.5 & 3 & 11.5 & \\
\hline Retired & 10 & 27.0 & 4 & 15.4 & \\
\hline \multicolumn{6}{|l|}{ Residence } \\
\hline Santa Maria & 29 & 78.4 & 21 & 80.8 & 0.817 \\
\hline Follow-up by mental health professional & 31 & 83.8 & 13 & 50.0 & 0.006 \\
\hline First consultation & 2 & 5.4 & 11 & 42.3 & $<0.001$ \\
\hline First admission & 6 & 16.2 & 16 & 61.5 & $<0.001$ \\
\hline Total no. of previous admissions (mean and SD) & 4.5 & 4.7 & 1.9 & 3.43 & 0.001 \\
\hline \multicolumn{6}{|l|}{ Number of previous admissions } \\
\hline 0 & 6 & 16.2 & 16 & 61.5 & $<0.001$ \\
\hline 1 to 4 & 16 & 43.2 & 6 & 23.1 & \\
\hline 5 or more & 15 & 40.5 & 4 & 15.4 & \\
\hline
\end{tabular}

$\mathrm{PHSA}=$ patients with a prior history of suicide attempt but no recent attempt; SA = patients who attempted suicide within 24 hours of admission; SD = standard deviation.

* College or vocational/technical schools.

+ Living arrangement had one missing value. 
most commonly cited (48.6 vs. $19.2 \%$; $p=0.020$ ). The length of hospitalization was longer in the PHSA group ( $\bar{x}=23 \pm 23$ vs. $\bar{x}=8 \pm 11$ days; $p=0.007)$. Table 2 presents the frequency of aggression and its relationship to recent suicide attempt. OAS scores presented no differences between the groups.
Analysis of the BPRS dimensions indicated that the SA group presented lower activation scores ( $\bar{x}=4 \pm 5$ vs. $\bar{x}=7 \pm 5 ; p=0.025)$ and higher affect $\operatorname{scores}(\bar{x}=$ $13 \pm 5$ vs. $\bar{x}=8 \pm 6 ; p=0.002)$. Other dimensions were not statistically significant.

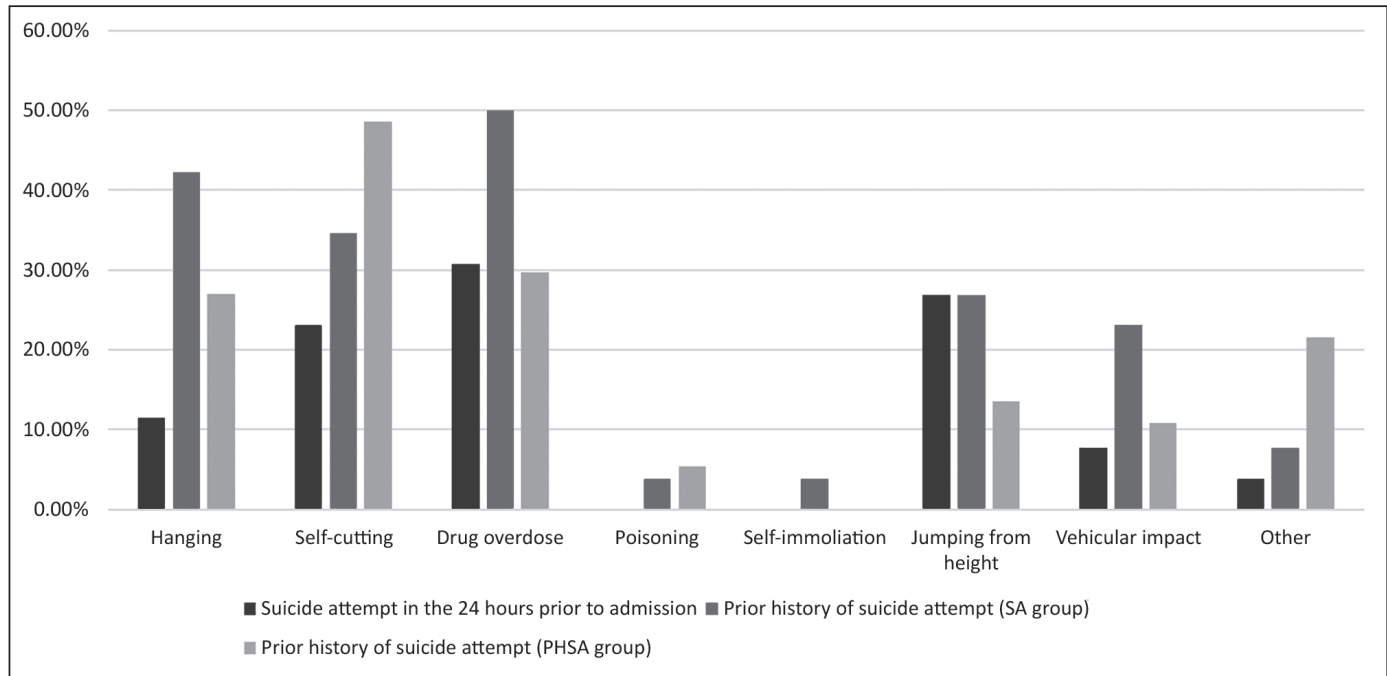

Figure 1 - Frequency of methods of suicide attempts in the last 24 hours prior to admission, compared to previous suicide attempts, in both groups. PHSA = patients with a prior history of suicide attempt but no recent attempt; SA = patients who attempted suicide within 24 hours of admission.

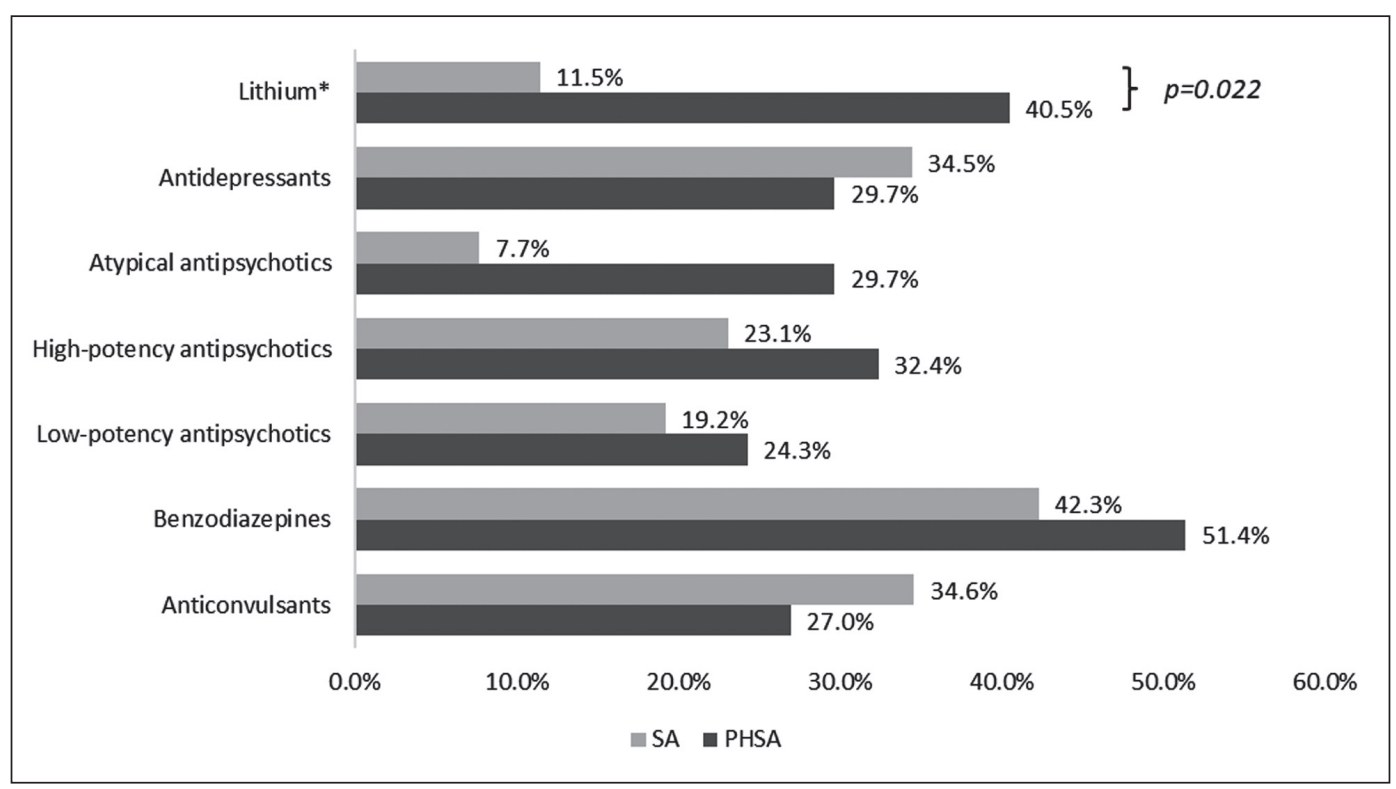

Figure 2 - Use of psychopharmaceutical at the time of admission. PHSA = patients with a prior history of suicide attempt but no recent attempt; $\mathrm{SA}=$ patients who attempted suicide within 24 hours of admission. 


\section{Discussion}

This study aimed to describe the profile of patients with a history of suicide attempt subjected to psychiatric hospitalization at a tertiary reference hospital serving the central micro-region of the state of Rio Grande do Sul, southern Brazil. Aggression was present in the majority of individuals with suicidal behaviors. The association between these phenomena was not directly tested; however, it is corroborated by various studies described in the literature. ${ }^{5-7,15-18}$

The profile of the patients who were admitted to the psychiatric ward of HUSM after a suicide attempt was mainly of young adults with low education, living with partners or families, employed, without previous psychiatric hospitalization, irregularly using psychopharmaceuticals, and with prior suicide attempt. The majority of the participants presented a history of aggression in the past and in the previous week. Twofifths remained aggressive during their hospitalization.

Participants as a whole had received previous emergency psychiatric treatment at the hospital, had used one or more psychopharmaceuticals (usually irregularly), and had a history of prior suicide attempt(s). The methods of suicide attempt were mainly drug overdose (with prescription drugs), jumping from height, and self-cutting. Previous studies have also found that suicide attempters were adults in their thirties, with low education and cohabiting. ${ }^{19,20}$

The main difference between the two groups analyzed in the present study was that the PHSA participants showed an increased risk of heteroaggression. They more commonly had a history of physical aggression in the week before admission. In the same way, they had more activation symptoms, but fewer depressive symptoms.

In the PHSA group, more patients were followed by a mental health professional, and they were receiving psychiatric treatment for more time. The PHSA group also had a higher number of previous psychiatric hospitalization and used more lithium. ${ }^{21}$ The literature points out that lithium is a medication that may reduce suicide attempts independently of its mood stabilizing effects. ${ }^{22,23}$ This may partly explain why previous suicide attempters, but not recent attempters, were more often taking lithium in our research.

The most common methods used in previous suicide attempts in the PHSA group were self-cutting, drug intake, and hanging. It is possible that suicide attempts and hetero-aggression in these patients were related and thus understandable as part of the same destructive tendency (whose expression was directed at the patients themselves, at others, or at both at different times). Some of our findings corroborate this hypothesis. Participants commonly presented a history of hetero-aggression and selfaggression (as much in the past as in the week before hospitalization; two-fifths were hostile upon checkin). Approximately half of the PHSA group reported episodes of physical aggression in the week before admission and were admitted due to the risk of hetero-aggression, while one-fifth of the SA group presented the same tendency. SA group participants were more depressed upon check-in, whereas PHSA group participants were more agitated. In previous studies, negative emotions expressed in the form

Table 2 - Relationship between suicide attempt and aggression

\begin{tabular}{|c|c|c|c|c|c|}
\hline & \multicolumn{2}{|c|}{ PHSA } & \multicolumn{2}{|c|}{ SA } & \multirow[b]{2}{*}{$\mathbf{p}$} \\
\hline & $\mathbf{n}$ & $\%$ & $\mathbf{n}$ & $\%$ & \\
\hline \multicolumn{6}{|l|}{ Prior history of aggression } \\
\hline Verbal/against objects & 34 & 91.9 & 24 & 92.3 & 1.000 \\
\hline Physical against others & 27 & 73.0 & 16 & 61.5 & 0.414 \\
\hline Physical against self & 26 & 70.3 & 16 & 61.5 & 0.589 \\
\hline \multicolumn{6}{|c|}{ History of aggression in the week prior to hospitalization } \\
\hline Verbal/against objects & 33 & 89.2 & 18 & 69.2 & 0.058 \\
\hline Physical against others & 19 & 51.4 & 5 & 19.2 & 0.017 \\
\hline Physical against self & 11 & 29.7 & 12 & 46.2 & 0.198 \\
\hline \multicolumn{6}{|c|}{ Aggression during hospitalization } \\
\hline Verbal/against objects & 16 & 43.2 & 10 & 38.5 & 0.797 \\
\hline Physical against others & 7 & 18.9 & 1 & 3.8 & 1.000 \\
\hline Physical against self & 5 & 13.5 & 2 & 7.7 & 1.000 \\
\hline
\end{tabular}

PHSA = patients with a prior history of suicide attempt but no recent attempt; SA = patients who attempted suicide within 24 hours of admission.

14 - Trends Psychiatry Psychother. 2019;41(1) 
of aggression and depression have been seen as motivation-forming factors for suicide attempt. ${ }^{24,25}$

The relationship between aggression, impulsiveness and suicidal behavior has been well established in the literature over the course of decades. ${ }^{15} \mathrm{~A}$ postmortem study found an association of impulsiveness and aggression with suicide in youths and a negative correlation with age. ${ }^{16}$ In a study developed in China with university students, impulsiveness was revealed to be a characteristic that could increase the likelihood of acting against one's own life, because it might facilitate the transition from suicidal thoughts to suicidal acts/ behavior. The literature also points out that students with higher aggression ratings are more likely to commit suicide. ${ }^{15}$ A study that compared individuals with non-suicidal self-aggression, without self-aggression and suicidal individuals found a higher prevalence of aggression among the first and third groups compared to the second, as well as a history of physical and/ or sexual abuse in childhood, anxiety disorder, and substance use disorder. ${ }^{17}$

The most prevalent diagnoses in our sample were precisely mood disorders, personality disorders, and substance use disorders. Impulsiveness and aggression are traits present in various disorders (mood disorders, substance abuse, personality disorders - primarily those in Cluster B). Impulsive-aggressive traits lead to increased suicide risk. ${ }^{16}$ The literature also suggests that impulsiveness and aggression can be seen as part of the same construct. ${ }^{15}$ One study reported that individuals with depression and bipolar disorder presented greater impulsiveness and aggression than controls. ${ }^{26}$ Impulsiveness may therefore be a marker for suicide risk, strongly correlated with aggression in individuals with mood disorders. Aggressive and suicidal behaviors also share psychological and biological correlates. ${ }^{15}$ In the same way, there is evidence supporting the role of emotion dysregulation and personality and behavior alterations in the occurrence of suicidal behavior among individuals with those psychiatric disorders. Special attention should be given to individuals with these diagnoses, because they are more likely to complete suicide. ${ }^{27}$ Furthermore, the methods chosen to attempt suicide may also have been related to impulsiveness and aggression among our participants. We found that violent methods were used to attempt suicide in the last 24 hours before admission in the majority of the SA group. Individuals who attempted suicide using violent methods presented higher impulsiveness and aggression than those who used methods considered nonviolent (poison, drowning, drug overdose, etc.). ${ }^{18}$ In Brazil, the methods most commonly employed for suicide are hanging and firearms (violent methods). ${ }^{28}$ Suicide attempts leading to hospitalization are more common in the presence of intoxication (alcohol, medication and poisoning). ${ }^{29}$ Completed suicide was most commonly observed in men, single individuals, and those using hanging, whereas nonlethal attempts predominated among women, with overdose of prescription drugs being the preferred method. ${ }^{30}$ Despite that, non-violent methods leading to hospitalization accounted for the minority of cases in our study.

Repeated suicide attempts were very common among participants. A literature review concluded that the main risk factor for repeated suicide attempts is having a history of a prior attempt and that the strongest suicide predictors are history of suicide attempt, advanced age, and/or high suicide ideation. ${ }^{31}$ In the same way, a recent study showed that after a first suicide attempt, the main risk factors for complete suicide are advanced age and hospitalization after the first attempt. ${ }^{32}$ The greatest risk of death by suicide is in the first year after an attempt, even for repeaters. ${ }^{33}$ Up to $90 \%$ of deaths by suicide occur over the first 24 months after an attempt. ${ }^{30}$

After discharge, there is a greater risk of suicide in the first week, primarily in individuals who live alone. A population-based cohort study conducted in Denmark reported that suicide attempts and suicides occurred more often in the first week after discharge from the emergency service. ${ }^{34}$ In the same study, the authors reported that $87 \%$ of the people who died by suicide had consulted an emergency department due to a suicide attempt only once - i.e., the next attempt was fatal. Uribe et al. found that suicide occurred most probably on the first or second attempt. ${ }^{34}$ These data emphasize the need for suicide prevention strategies targeted at people receiving care for suicide attempts, since it is well-known that suicide attempt is the main risk factor for completed suicide, as shown by a metanalysis of 24 studies of psychological autopsies. ${ }^{35}$

A Brazilian study showed that only one-third of the people who attempted suicide sought treatment at an emergency service. ${ }^{36}$ In this sense, aggression and impulsiveness could serve as markers for future suicide attempt, and the individuals presenting these traits should be referred to a mental health service for evaluation. Future research shall seek to investigate this.

Our study has some limitations. We did not assess all clinical factors that are related to suicide attempts (e.g., acute and chronic stress exposure and life adversities). In addition, sample size did not allow for the calculation of predictive values of measures or for the inclusion, in our analyses, of clinical factors that could also be associated with a recent suicide 
attempt (e.g., drug and alcohol dose). There is also the possibility of confounding effects of the psychiatric medications. In the same way, we do not know the length of time elapsed since the most recent suicide attempt for participants who attempted suicide in their lifetime but not in the previous week (PHSA group). As well, the study did not have a control group, and this is because of its naturalistic design. Thus, even though the methodology employed here does not allow assessing risk factors for suicide attempt, it does allow raising considerations about this particular profile of patients, and helps improve our understanding of the problem. In addition, due to the exploratory nature of our study, we did not adjust for multiple comparisons. Despite the fact that this paper used appropriate statistical tests, generalization of the results is not possible, and no further assumptions can be made. Notwithstanding, exploratory and comparative designs are useful to provide means for generating hypotheses to be tested in future studies.

The association between aggression and suicide is well supported in the literature. If not every suicide attempt is motivated by impulsiveness and aggression, our study shows that the phenomena may be observed jointly in a significant portion of the patients hospitalized for suicidal behavior. Our exploratory comparative design showed differences between the groups in terms of reason for hospital admission, use of lithium, and duration of psychiatric treatment before hospital admission. The differences found in terms of the presence of an aggressive episode in the week prior to admission may provide soil for future research. It is suggested, as a public health strategy, that individuals hospitalized for suicide attempt and/or with a history of aggression be properly followed for preventing suicide.

\section{Acknowledgements}

We thank the research team for their joint efforts, in particular Amadeu Antonio Bertuol Filho, José Antônio Fereira Reis de Lima, and Prof. Dr. Angelo B. M. Cunha. This study was funded by Programa de Iniciação Científica do Hospital Universitário de Santa Maria (PROIC-HUSM).

\section{Disclosure}

No conflicts of interest declared concerning the publication of this article.

\section{References}

1. World Health Organization. Preventing suicide. CMAJ. 2014;143:609-10.

2. Brasil, Ministério da Saúde, Departamento de Informática do SUS (DATASUS). Informações de saúde. Óbitos por causas externas Rio Grande do Sul [Internet]. [cited 2017 Nov 21]. http://www2. datasus.gov.br/DATASUS/index.php?area $=0205 \& \mathrm{id}=25108041$ \&VObj=http://tabnet.datasus.gov.br/cgi/deftohtm.exe?sim/cnv/ evitb10

3. Machado DB, dos Santos DN. Suicídio no Brasil, de 2000 a 2012. J Bras Psiquiatr. 2015;64:45-54.

4. Hawton K, van Heeringen K. Suicide. Lancet. 2009;373:137281.

5. McGirr A, Renaud J, Bureau A, Seguin M, Lesage A, Turecki G. Impulsive-aggressive behaviours and completed suicide across the life cycle: a predisposition for younger age of suicide. Psychol Med. 2008;38:407-17.

6. Kerr DCR, Capaldi DM. Young men's intimate partner violence and relationship functioning: Long-term outcomes associated with suicide attempt and aggression in adolescence. Psychol Med. 2010;14:1-11.

7. Swogger MT, Walsh Z, Maisto SA, Conner KRA. Reactive and proactive aggression and suicide attempts among criminal offenders. Crim Justice Behav. 2014;41:337-44.

8. Calegaro VC, Dott AB, Freitas D, Brum AB, Valerio AG, Schetinger CC, et al. Comportamento agressivo durante as primeiras 24 horas de internação psiquiátrica. Trends Psychiatry Psychother. 2014;36:152-9.

9. Overall JE, Gorham DR. The Brief Psychiatric Rating Scale. Psychol Rep. 1962;10:799-812.

10. Silver JM, Yudofsky SC. The Overt Aggression Scale: overview and guiding principles. J Neuropsychiatry Clin Neurosci. 1992;3:S229.

11. Romano F, Elkis H. Tradução e adaptação de um instrumento de avaliação psicopatológica das psicoses: A Escala Breve de Avaliação Psiquiátrica - Versão Ancorada (BPRS-A). J Bras Psiquiatr. 1996;45:43-9.

12. Crippa JA, Sanches RF, Hallak JEC, Loureiro SR, Zuardi AW. Structured interview guide increases Brief Psychiatric Rating Scale reliability in raters with low clinical experience. Acta Psychiatr Scand. 2001;103:465-70.

13. Shafer A. Meta-analysis of the Brief Psychiatric Rating Scale factor structure. 2005;17:324-35.

14. Mackinnon RA, Yudofsky SC. Avaliação psiquiátrica. Porto Alegre: Artes Médicas; 1988.

15. Gvion Y, Apter A. Aggression, impulsivity, and suicide behavior: a review of the literature. Arch Suicide Res. 2011;15:93-112.

16. McGirr A, \& Turecki G. The relationship of impulsive aggressiveness to suicidality and other depression-linked behaviors. Curr Psychiatry Rep. 2007;9:460-6.

17. Chartrand H, Candidate MA, Bhaskaran J, Sareen J, Katz LY, Bolton JM. Correlates of nonsuicidal self-injury and suicide attempts among tertiary care, emergency department patients. Can J Psychiatry. 2015;60:276-83.

18. Dumais $A$, Lesage AD, Lalovic A, Séguin M, Tousignant $M$, Chawky, $\mathrm{N}$, et al. Is violent method of suicide a behavioral marker of lifetime aggression? Am J Psychiatry. 2005;162:1375-8.

19. Engström G, Alling C, Gustavsson P, Oreland L, TräskmanBendz L. Clinical characteristics and biological parameters in temperamental clusters of suicide attempters. ] Affect Disord. 1997:44:45-55.

20. Rapeli, CB, Botega, NJ. Clinical profiles of serious suicide attempters consecutively admitted to a university-based hospital: a cluster analysis study. Rev Bras Psiquiatr. 2005;27:285-9.

21. Lewitzka U, Severus $E$, Bauer R, Ritter $P$, Müller-Oerlinghausen $B$, Bauer $M$. The suicide prevention effect of lithium: more than 20 years of evidence-a narrative review. Int J Bipolar Disord. 2015;3:32.

22. Baldessarini RJ, Innamorati M, Erbuto D, Serafini G, Fiorillo A, Amore $M$, et al. Differential associations of affective temperaments and diagnosis of major affective disorders with suicidal behavior. J Affect Disord. 2017;210:19-21.

23. Mann, JJ. Neurobiology of suicidal behaviour. Nat Rev Neurosci. 2003;4:819-28. 
24. Boergers J, Spirito A, Donaldson D. Reasons for adolescent suicide attempts: associations with psychological functioning. J Am Acad Child Adolesc Psychiatry. 1998;37:1287-93.

25. Brown MZ, Comtois KA, Linehan MM. Reasons for suicide attempts and nonsuicidal self-injury in women with borderline personality disorder. J Abnorm Psychol. 2002;111:198-202.

26. Perroud N, Baud P, Mouthon D, Courtet $P$, Malafosse A. Impulsivity, aggression and suicidal behavior in unipolar and bipolar disorders. ] Affect Disord. 2011;134:112-8.

27. Bertolote JM, Fleischmann A. Suicide and psychiatric diagnosis: a worldwide perspective. World Psychiatry. 2002;1:181-5.

28. Lovisi GM, Santos SA, Legay L, Abelha L, Valencia E. Análise epidemiológica do suicídio no Brasil entre 1980 e 2006. Rev Bras Psiquiatr. 2006;31(Supl II):86-94.

29. Silveira R, Santos A, Ferreira L. Impact of morbi-mortality and expenses with suicide in brazil from 1998 to 2007. Rev Pesq Cuidado Fundamental Online. 2012;4:3033-42.

30. Vidal CEL, Gontijo ECDM, Lima LA. Tentativas de suicídio: fatores prognósticos e estimativa do excesso de mortalidade. Cad Saude Publica. 2013;29:175-87.

31. Beghi M, Rosenbaum JF, Cerri C, Cornaggia CM. Risk factors for fatal and nonfatal repetition of suicide attempts: a literature review. Neuropsychiatr Dis Treat. 2013;9:1725-36.

32. Fedyszyn IE, Erlangsen A, Hjorthøj C, Madsen T, Nordentoft M. Repeated suicide attempts and suicide among individuals with a first emergency department contact for attempted suicide: a prospective, nationwide, Danish register-based study. J Clin Psychiatry. 2016;77:e1-e9.

33. Christiansen E, Jensen BF. Risk of repetition of suicide attempt, suicide or all deaths after an episode of attempted suicide: a register-based survival analysis. Aust $\mathrm{N} Z \mathrm{Z}$ J Psychiatry. 2007; 41:257-65.

34. Uribe PI, Blasco-Fontecilla H, García-Parés G, Giró Batalla M, Llorens Capdevila M, Cebrià Meca A, et al. Attempted and completed suicide: not what we expected? J Affect Disord. 2013;150:840-6.

35. Yoshimasu K, Kiyohara C, Miyashita K. Suicidal risk factors and completed suicide: Meta-analyses based on psychological autopsy studies. Environ Health Prev Med. 2008;13:243-56.

36. Botega NJ, Marín-León L, de Oliveira HB, Barros MBDA, da Silva VF, et al. Prevalências de ideação, plano e tentativa de suicídio: um inquérito de base populacional em Campinas, São Paulo, Brasil. Cad Saude Publica. 2009;25:2632-38.

\section{Correspondence:}

Vitor Crestani Calegaro

Tel.: +55 (55) 3220.8427

Av. Roraima, $s / n^{\circ}$, Prédio 26

97195-000 - Santa Maria, RS - Brazil

E-mail: vitorcalegaro@mail.ufsm.br 